\title{
miR-600 inhibits cell proliferation, migration and invasion by targeting p53 in mutant p53-expressing human colorectal cancer cell lines
}

\author{
PEILI ZHANG $^{1 *}$, ZHIGUI ZUO ${ }^{2 *}$, AIHUA WU ${ }^{1}$, WENJING SHANG ${ }^{1}$, \\ RUICHUN BI ${ }^{1}$, QIKE JIN ${ }^{1}$, JIANBO WU ${ }^{1}$ and LEI JIANG ${ }^{1}$ \\ ${ }^{1}$ Central Laboratory and ${ }^{2}$ Department of Colorectal Surgery, \\ The First Affiliated Hospital of Wenzhou Medical University, Wenzhou, Zhejiang 325000, P.R. China
}

Received January 22, 2016; Accepted November 1, 2016

DOI: $10.3892 / 01.2017 .5654$

\begin{abstract}
Mutations of the tumor protein p53 gene, a tumor suppressor, are one of the most frequent genetic alterations observed in cancer. It has been reported that mutations in p53 result in the loss of wild-type p53 activity, and the gain of novel oncogenic properties that promote tumor growth and progression. Recent studies have demonstrated that a number of microRNAs (miRs) are involved in the post-transcriptional regulation of $\mathrm{p} 53$. The present study demonstrates that miR-600 is a direct negative regulator of $\mathrm{p} 53$ through binding a site in the 3' untranslated region of p53 mRNA in human colorectal cancer (CRC) cells. Overexpression of miR-600 by lentiviral-mediated transduction decreased endogenous levels of p53 protein and inhibited cell proliferation, migration and invasion in mutant p53-expressing human CRC cell lines (SW480, SW620 and DLD-1) in vitro. In addition, silencing of p53 with small interfering RNA led to a similar phenotype. Furthermore, overexpression of miR-600 or p53 knockdown suppressed the expression of matrix metalloproteinase 9 , and promoted the expression of E-cadherin and $\beta$-catenin. The results of the current study demonstrate that miR-600 is an important negative regulator of $\mathrm{p} 53$, and suggest that targeting mutant p53 using lentiviral-mediated miR-600 overexpression is a promising therapeutic strategy for the treatment of CRCs with p53 mutations.
\end{abstract}

Correspondence to: Dr Lei Jiang, Central Laboratory, The First Affiliated Hospital of Wenzhou Medical University, 2 Fuxue Lane, Wenzhou, Zhejiang 325000, P.R. China

E-mail: jiangleistone79@163.com

${ }^{*}$ Contributed equally

Key words: microRNA-600, mutant p53, lentiviral vector, colorectal cancer, migration, invasion

\section{Introduction}

Colorectal cancer (CRC) is the third most common cancer worldwide, and is a major cause of morbidity and mortality (1). Specifically, CRC is the third most frequent cancer observed in males and the second most frequent cancer in females (2). CRC represents $\sim 9 \%$ of all cancer cases (3). Diagnosis of and therapy for CRC have advanced significantly over the last ten years; however, 5-year survival rates remain poor (4). Therefore, there is a requirement for the development of novel therapeutic agents with a high efficacy for the treatment of CRC.

The tumor suppressor protein $\mathrm{p} 53$, encoded by the tumor protein p53 (TP53) gene, prevents the development and progression of cancer through regulation of a range of cellular mechanisms, including apoptosis, cell cycle arrest, metabolism and DNA repair $(5,6)$. In total $\sim 50 \%$ of all human cancers have mutations in TP53 that lead to the production of functionally inactive p53 (7-9). In addition, these mutations frequently induce tumor-promoting actions through dominant-negative inactivation of the remaining wild-type TP53 allele, or apoptosis resistance, increased tumor aggressiveness and metastatic potential $(6,10,11)$. Furthermore, gain-of-function TP53 mutations may produce mutant $\mathrm{p} 53$ protein, which exhibits oncogenic effects, including increased cell proliferation, invasion, metastasis and drug resistance, and inhibition of apoptosis (12).

A previous study demonstrated that $\mathrm{p} 53$ is able to regulate the expression of specific microRNAs (miRs), which contributes to tumor suppression by controlling the expression of the targets of these miRs, which include key effectors of numerous cellular processes, for example cell cycle progression, epithelial-mesenchymal transition, stemness, metabolism, cell survival and angiogenesis (13). Reciprocally, the activity of p53 has been observed to be under the control of several miRNAs, including miR-125 and miR-504, which were identified to negatively regulate $\mathrm{p} 53$ expression by directly targeting the 3'untranslated region (UTR) of TP53 $(14,15)$. In addition, previous studies have reported that several miRNAs (miR-29, miR-34a, miR-122, miR-192, miR-194 and miR-215) positively regulate p53 expression (16-21). miRs are short non-coding RNAs of between 18 and 24 nucleotides in length, which participate in numerous biological pathways through 
regulating the post-transcriptional expression of genes (22). In total $\sim 1,400 \mathrm{miRs}$ have been identified in humans thus far, and miRs have been demonstrated to serve important roles in the pathogenesis of disease (23). For example, miRs have been reported to regulate the expression of their target mRNAs to affect tumor growth, invasion and angiogenesis in cancer $(24,25)$.

In the present study, bioinformatic analysis, performed using TargetScan Software (version 6.2; www.targetscan.org/vert_61), identified that the 3'UTR of p53 mRNA contains a putative miR-600 binding site. Subsequent ectopic overexpression of miR-600 in vitro using lentiviral-mediated transduction was observed to decrease cell proliferation, migration and invasion in mutant p53-expressing human CRC cell lines, indicating that miR-600 targets p53 mRNA for degradation in this context. Furthermore, overexpression of miR-600 inhibited the expression of matrix metalloproteinase 9 (MMP-9) and promoted the expression of E-cadherin and $\beta$-catenin proteins. Similar results were obtained when p53 expression was silenced using small interfering RNA (siRNA). These results suggest that targeting the miR-600/p53 network may lead to the identification of novel therapeutic agents for the treatment of CRC.

\section{Materials and methods}

Cell culture. Human CRC cell lines (SW480, SW620 and DLD-1) and human embryonic kidney cells (HEK293T) were obtained from the Type Culture Collection of the Chinese Academy of Sciences (Shanghai, China). SW480 and DLD-1 cells were cultured in RPMI-1640 medium, and SW620 and HEK293T cells were cultured in Dulbecco's modified Eagle's medium (both Invitrogen; Thermo Fisher Scientific, Inc., Waltham, MA, USA). All media was supplemented with $10 \%$ fetal bovine serum (FBS) and $100 \mathrm{U} / \mathrm{ml}$ penicillin and streptomycin (both Invitrogen; Thermo Fisher Scientific, Inc.). All cells were maintained at $37^{\circ} \mathrm{C}$ in an incubator with $5 \% \mathrm{CO}_{2}$.

siRNA transfection. A siRNA was designed to target the human p53 gene based on the public GenBank sequence (https://www.ncbi.nlm.nih.gov/genbank/) and was purchased from GenePharma Co., Ltd. (Shanghai, China). The sequence of p53 siRNA was 5'-GACUCCAGUGGUAAUCUAC-3'. The sequence of scramble siRNA (control) was 5'-GCAACGGCA UUCCACCUUU-3'. SW620, SW480 and DLD-1 cells $\left(2 \times 10^{4}\right.$ cells/well) were seeded into 6-well plates and were transfected with $50 \mu \mathrm{M}$ scramble siRNA [Negative control (NC)] or p53-siRNA using Lipofectamine 3000 (Invitrogen; Thermo Fisher Scientific, Inc.) according to the manufacturer's protocol.

Lentiviral vector construction for miR-600 overexpression. Hsa-miR-600 sequence was obtained from miRBase database (www.mirbase.org). For the construction of the lentiviral vector expressing miR-600, miR-600 precursors and their native context sequences (upstream and downstream flanking genomic sequences) were amplified from HEK293T cell genomic DNA using polymerase chain reaction (PCR) with the Takara Ex Taq ${ }^{\mathrm{TM}}$ Hot Start Version kit (Takara Bio, Inc., Otsu, Japan). The PCR reaction conditions were as follows: $94^{\circ} \mathrm{C}$ for $5 \mathrm{~min}$, followed by $94^{\circ} \mathrm{C}$ for $45 \mathrm{sec}, 60^{\circ} \mathrm{C}$ for $45 \mathrm{sec}$ and $72^{\circ} \mathrm{C}$ for $1 \mathrm{~min}$, for a total of 30 cycles; a final step at $72^{\circ} \mathrm{C}$ for $10 \mathrm{~min}$ was subsequently performed. The following primers were used for PCR: Forward-SalI, 5'-gcggtcgacTACTCCTTGATCCATTTCCAT-3'; and reverse-EcoRI, 5'-ggaattcaaaaaGGAACACTTCTTGCATTGTCT-3' (uppercase letters indicate the coding primer sequence; lowercase letters refer to the enzyme loci and the protective bases). The resulting PCR product was digested with SalI and EcoRI prior to insertion into a human U6 promoter-containing pBluescript SK (+) plasmid. The construct obtained was then digested with SalI and EcoRI, then U6 promoter and subsequent pre-miR-600 genomic fragments were cloned into the lentiviral plasmid pLUNIG as previously described $(26,27)$. A lentiviral vector expressing a short hairpin (sh) RNA targeting firefly luciferase (shLuc target sequence, 5'-TGC GCTGCTGGTGCCAACCCTATTCT-3') was used as the control, as previously described $(26,27)$. Vesicular stomatitis virus GP pseudotyped lentiviruses were produced by co-transducing HEK293T cells with lentivirus expression and packaging plasmids (pMD2.G, pMDL-G/P-RRE and pRSV-REV). A total of $5 \times 10^{4}$ CRC cells (SW480, SW620 or DLD-1) were then transduced with the lentiviruses (lentiviral vector expressing miR-600 or control) in the presence of $8 \mu \mathrm{g} / \mathrm{ml}$ Polybrene (Sigma-Aldrich; EMD Millipore, Billerica, MA, USA).

Cell viability assay. Cell viability was measured using the MTT assay. Briefly, cells were seeded into 96-well plates at a density of $2 \times 10^{3}$ cells/well and cultured at $37^{\circ} \mathrm{C}$ for $1,2,3$ or 4 days. At these time points, $20 \mu \mathrm{l}$ of MTT $(5 \mathrm{mg} / \mathrm{ml})$ solution was added to each well and cells were incubated for an additional $4 \mathrm{~h}$ at $37^{\circ} \mathrm{C}$. The formazan product was dissolved with dimethyl sulfoxide and plates were incubated for $10 \mathrm{~min}$ at room temperature. A microplate reader was subsequently used to measure the absorbance at $490 \mathrm{~nm}$. Each condition was determined in quintuplicate, and all experiments were repeated $\geq 3$ times

Cell migration and invasion assays. In vitro cell migration and invasion assays were performed in 24-well Transwell cell culture chambers with $8 \mu \mathrm{m}$ pores (Costar; Corning Incorporated, Cambridge, MA, USA) according to the manufacturer's instructions. For the migration assay, DLD-1, SW480 and SW620 cells in starvation medium (without FBS) $\left(2.5 \times 10^{5} / 100 \mu \mathrm{l}\right)$ were seeded into the Transwell filter membrane chambers and incubated at $37^{\circ} \mathrm{C}$ for 16,24 or $48 \mathrm{~h}$, respectively. The appropriate culture medium supplemented with $10 \%$ FBS was added to the lower chambers as a chemoattractant. Following incubation, cells in the lower chambers were fixed using $4 \%$ paraformaldehyde and stained with $0.1 \%$ crystal violet solution. Cells that did not migrate were removed from the upper chamber surface using a cotton swab, and the number of cells that migrated to the lower chamber was counted in $\geq 5$ fields (fields were randomly selected under a light microscope at magnification, x20). For the invasion assay, Transwell membranes were pre-coated with $10 \mu \mathrm{l}$ of Matrigel (diluted 1:3; BD Biosciences, San Jose, CA, USA) prior to the process described above.

Western blot analysis. Cells were lysed in a radioimmunoprecipitation assay lysis buffer (Sigma-Aldrich; EMD 
Millipore) containing a protease inhibitor cocktail (Thermo Fisher Scientific, Inc.). The total concentration of protein obtained was measured using the Pierce BCA Protein Assay kit (Thermo Fisher Scientific, Inc.). Total protein $(30 \mu \mathrm{g})$ was separated by SDS-PAGE using an 8 or $12 \%$ gel and subsequently transferred onto polyvinylidene difluoride membranes (EMD Millipore). Membranes were blocked in $5 \%$ skimmed milk (BD Biosciences) for $1 \mathrm{~h}$ at room temperature and incubated with primary antibodies overnight at $4^{\circ} \mathrm{C}$. Subsequently, the membranes were incubated with the appropriate horseradish peroxidase-conjugated secondary antibody for $1 \mathrm{~h}$ at room temperature. Antibody binding was detected using an enhanced chemiluminescence detection system (GE Healthcare Life Sciences, Pittsburgh, PA, USA). The following primary antibodies were used: Mouse anti-E-cadherin (diluted 1:3,000; \#610181; BD Biosciences) and anti-vimentin (diluted 1:3,000; \#5550513; BD Biosciences), rabbit anti-p53 (diluted 1:500; ab31333; Abcam, Cambridge, UK), rabbit anti-Slug (diluted 1:1,000; \#9585) and anti- $\beta$-actin (diluted 1:1,000; \#4970, Cell Signaling Technology, Inc., Danvers, MA, USA), mouse anti-fibronectin (diluted 1:100; SC18825) and anti- $\beta$-catenin (diluted 1:100; SC7199; Santa Cruz Biotechnology, Inc., Santa Cruz, CA, USA), and rabbit anti-MMP-9 (diluted 1:1,000; BS1241; Bioworld Technology, Inc., St. Louis Park, MN, USA). The secondary antibody was horseradish peroxidase-conjugated goat anti-rabbit (diluted 1:2,000; ab6721; Abcam) or rabbit anti-mouse (diluted 1:2,000; ab6728; Abcam) secondary antibody.

Dual-luciferase reporter assay. Putative targets of miR-600 were predicted using TargetScan Software (version 6.2; www.targetscan.org/vert_61). DNA fragments corresponding to the 3'UTR of TP53 mRNA containing the putative miR-600 binding site (wt-P53-3'UTR-sense with SpeI site, 5'-CTAGTTACTGTGAGGGATGTTTGGGAG ATGTAAGAAATGTTCTTGA-3' and wt-P53-3'UTR-antisense with HindIII site, 5'-AGCTTCAAGAACATTTCT TACATC TCCCAA ACATCCCTCACAGTAA-3'), or a mutated version of this site (mut-P53-3'UTR-sense with SpeI site, 5'-CTAGTTACTGTGAGGGATGTTTGGGAGATA GACGAAATGTTCTTGA-3' and mut-P53-3'UTR-antisense with HindIII site, 5'-AGCTTCAAGAACATTTCGTCT ATCTCCCAAACATCCCTCACAGTAA-3'), were chemically synthesized and cloned into the SpeI and HindIII sites of pMIR-REPORT luciferase vector (Thermo Fisher Scientific, Inc.). HEK293T cells were seeded into a 24 -well plate at a density of $3 \times 10^{5}$ cells/well and co-transduced with pMIR-REPORT-wt-P53-3'UTR or pMIR-REPORT-mut-P53-3'UTR and miR-600 expression plasmids, and a Renilla plasmid (RLSV40; Promega Corporation, Madison, WI, USA) as internal normalization. Cells were cultured at $37^{\circ} \mathrm{C}$ in an incubator with $5 \% \mathrm{CO}_{2}$ for $48 \mathrm{~h}$, and then cells were lysed using Passive Lysis Buffer (Promega Corporation). Luciferase activity was detected using the Dual-Luciferase Reporter Assay kit (Promega Corporation) according to the manufacturer's instructions. Results were obtained from three independent repeats.

Statistical analysis. One-way analysis of variance (ANOVA) and Student's $t$-test were used to statistically compare differ- ences between groups. Post-hoc tests (Student-Newman-Keuls method) were used following performance of ANOVA. Statistical analysis was performed using SPSS software (version 15.0; SPSS, Inc., Chicago, IL, USA). Results are presented as the mean \pm standard deviation. $\mathrm{P}<0.05$ was considered to indicate a statistically significant difference.

\section{Results}

miR-600 reduces $C R C$ cell viability, migration and invasion in vitro. To investigate the effects of miR-600 on CRC cell growth, migration and invasion, SW480, SW620 and DLD-1 cells were transduced with lentiviral vectors expressing miR-600 or the control. The MTT assay was performed to determine cell viability (Fig. 1). As shown in Fig. 1A, the viability of SW480 cells transduced with miR-600-containing lentivirus was significantly suppressed compared with the control group 3 and 4 days following transduction $(\mathrm{P}<0.0001)$. Similar results were observed in SW620 and DLD-1 cells 3 and 4 days post-transduction $(\mathrm{P}<0.0001$ vs. the control group; Fig. 1A). The impact of miR-600 overexpression on cell migration and invasion abilities was measured using Transwell assays in vitro. This identified that miR-600 overexpression significantly decreased migration and invasion abilities of SW480 ( $\mathrm{P}<0.0001$; Fig. 1B), SW620 ( $\mathrm{P}<0.0001$; Fig. 1C) and DLD-1 (migration, $\mathrm{P}=0.0008$ and invasion, $\mathrm{P}=0.0001$, Fig. 1D) cells compared with the control group. These results suggest that the overexpression of miR-600 inhibits proliferation, migration and invasion in human CRC cells.

p53 is a direct target of miR-600 in CRC cells. To identify the molecular target involved in miR-600 regulation of CRC cell proliferation, migration and invasion, the effects of mutant p53 protein expression were investigated in CRC cells. As shown in Fig. 2A, overexpression of miR-600 by lentiviral-mediated transduction inhibited p53 protein expression in SW480, SW620 and DLD-1 CRC cells. To further investigate whether p53 is a direct target of miR-600, bioinformatic analysis was performed using TargetScan software. This revealed a putative miR-600 binding site in the 3'UTR of p53 mRNA (Fig. 2B).

A luciferase reporter assay was subsequently performed to determine whether miR-600 directly targeted the 3'UTR of p53 mRNA in vitro. A fragment of the 3'UTR of p53 with a wild-type or mutant miR-600 target binding site was cloned into the pMIR-REPORT luciferase reporter vector. The results of the dual-luciferase reporter assay demonstrated that miR-600 significantly suppressed luciferase reporter activity at the wild-type p53 3'UTR site $(\mathrm{P}=0.0044$ vs. the control group), whereas mutation of the miR- 600 binding site blocked this suppressive effect ( $\mathrm{P}=0.0014$ vs. wild-type site; Fig. 2C). These results indicate that miR-600 directly targets the 3 'UTR of p53 mRNA to downregulate the expression of p53 protein.

miR-600 modulates epithelial-mesenchymal transition (EMT)-associated protein expression by targeting p53 mRNA in mutant p53-expressing human CRC cell lines. The expression levels of proteins associated with EMT proteins were detected through western blotting (Fig. 2D). Levels of the epithelial cell marker proteins E-cadherin and $\beta$-catenin, were increased in CRC cell lines (SW480, SW620 and DLD-1) over- 
A

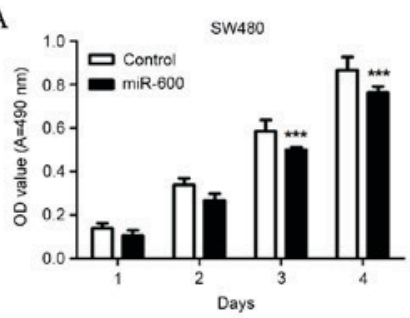

B

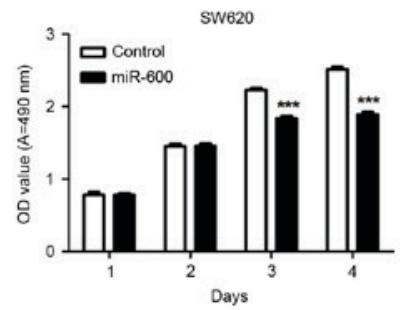

SW480

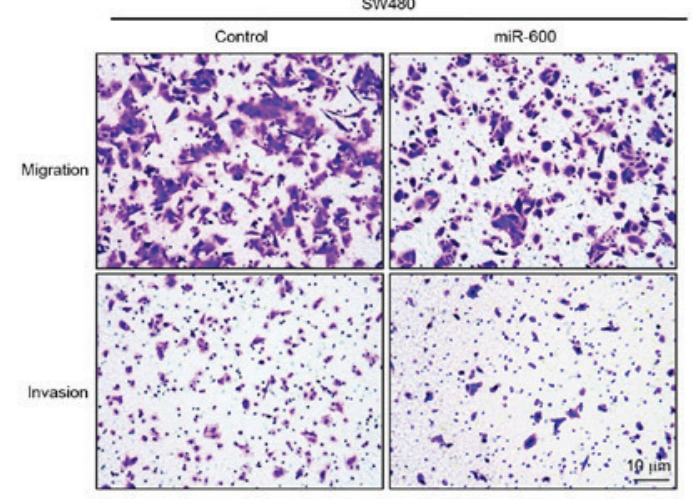

C

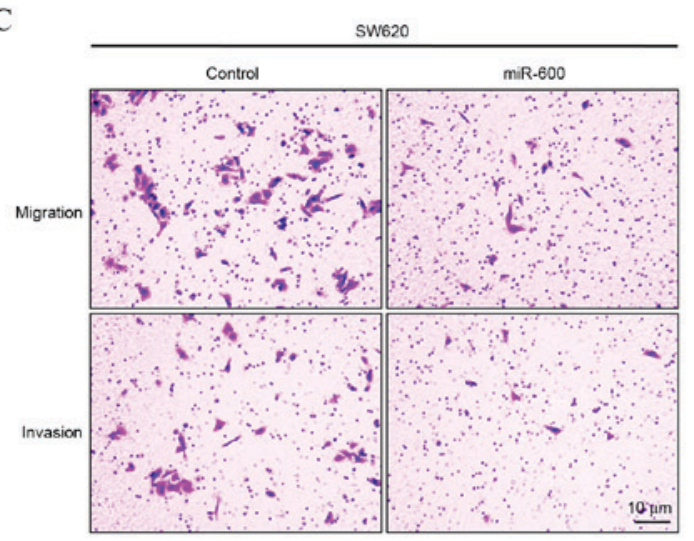

$\mathrm{D}$

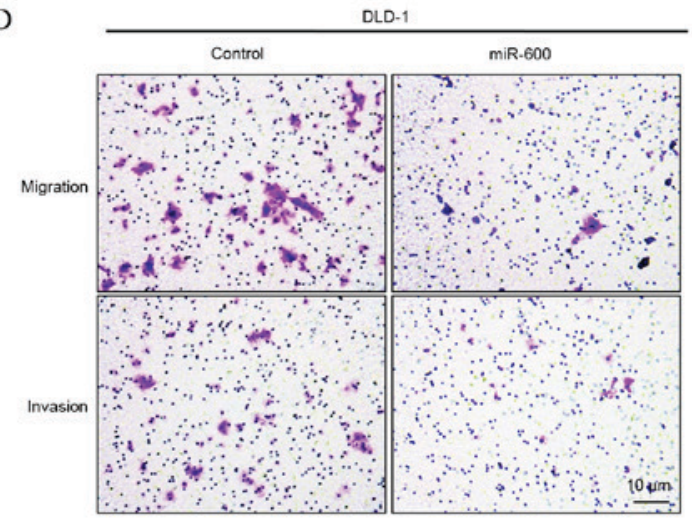

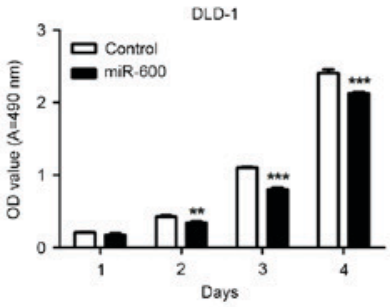
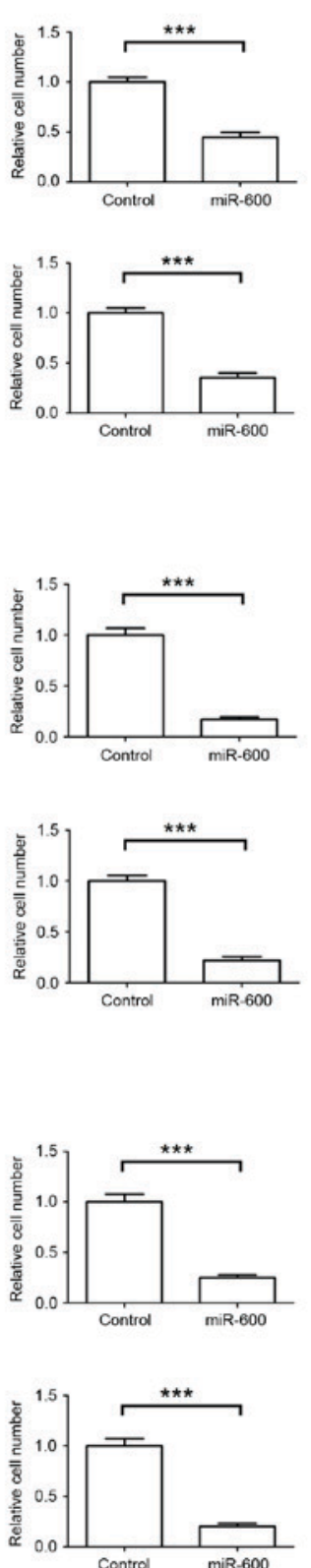

Figure 1. Ectopic overexpression of miR-600 through lentiviral-mediated transduction inhibits CRC cell proliferation, migration and invasion in vitro. (A) Effect of miR-600 overexpression on the viability of CRC cell lines SW480, SW620 and DLD-1. Effect of miR-600 on the migration and invasion abilities of (B) SW480, (C) SW620 and (D) DLD-1 cells. Magnification, x200; Scale bars, $10 \mu \mathrm{m} .{ }^{* *} \mathrm{P}<0.01,{ }^{* * *} \mathrm{P}<0.001$ vs. the control group. CRC, colorectal cancer; miR, microRNA; OD, optical density; A, absorbance.

expressing miR-600. In addition, protein levels of MMP-9, a member of the MMP family, appeared to be decreased in CRC cells overexpressing miR-600.
siRNA silencing of mutant 533 expression reduces cell viability, migration and invasion in mutant p53-expressing human CRC cell lines. The effects of p53 mutation on CRC cell viability, 
A

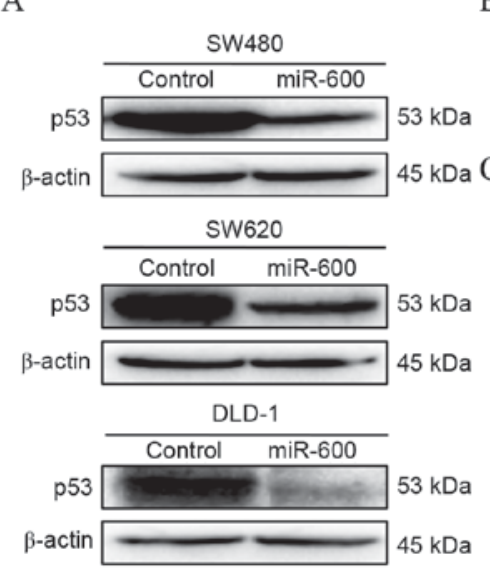

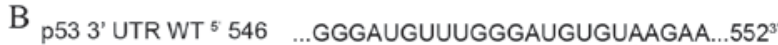

|| || || |

Hsa-miR-600 '" CUCGUUCCGAGAACAGACAUUCA

p53 3' UTR mut ${ }^{5} 546 \quad$...GGGAUGUUUGGGAGAUAGACGAA...552

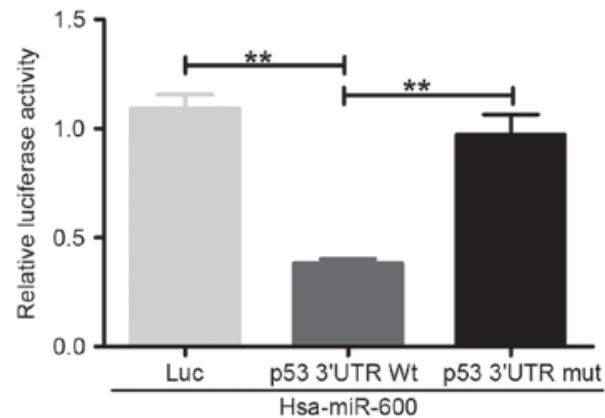

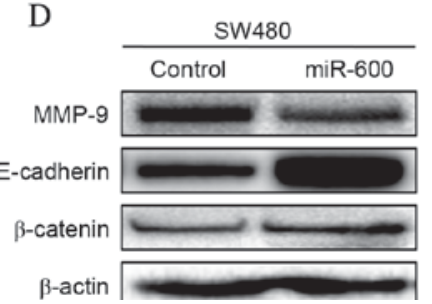
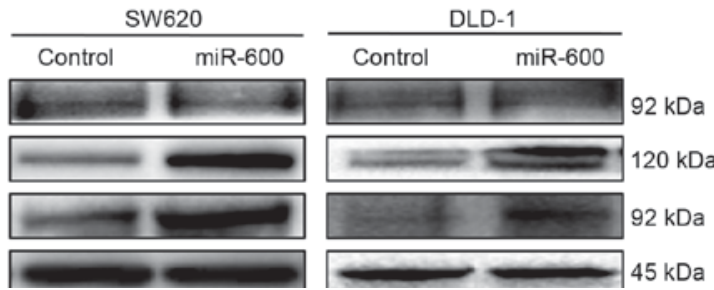

Figure 2. miR-600 influences the expression of EMT-associated proteins by targeting p53 in mutant p53-expressing human CRC cell lines. (A) Western blotting revealed that overexpression of miR-600 through lentiviral-mediated transduction inhibited p53 protein expression in CRC cell lines SW480, SW620 and DLD-1. (B) The putative miR-600 binding site of the 3'UTR of WT and mut p53 mRNA. Underlining indicates the sites of mutation. (C) Overexpression of miR-600 suppressed the activity of the luciferase reporter containing the 3' UTR of WT p53, but not the reporter with the 3' UTR of mut p53. (D) Western blotting demonstrated that overexpression of lentiviral-mediated miR-600 overexpression resulted in increased expression of E-cadherin and $\beta$-catenin, and decreased expression of MMP-9. $\beta$-actin was used as a protein-loading control. " $\mathrm{P}<0.01$. miR, microRNA; WT, wild-type; mut, mutant; Luc, luciferase control; UTR, untranslated region; MMP-9, matrix metalloproteinase 9.

migration and invasion were further investigated in vitro using the MTT assay, and Transwell migration and invasion assays, respectively. These assays demonstrated that knockdown of mutant p53 expression in SW480, SW620 and DLD-1 cells significantly decreased cell viability compared with the control group at 3 and 4 days post-transfection ( $\mathrm{P}<0.001$; Fig. 3A). In addition, the knockdown of mutant p53 expression in SW480 cells significantly reduced cell migration (91.6\%) and invasion $(75.6 \%)$ abilities $(\mathrm{P}<0.0001$ vs. the control group; Fig. 3B). Similarly, migration and invasion were decreased by $79.3 \%$ $(\mathrm{P}=0.0003)$ and $84.2 \%(\mathrm{P}=0.0019)$, respectively, in SW620 cells (Fig. 3C), and 78.9\% $(\mathrm{P}<0.0001)$ and $72.2 \%(\mathrm{P}=0.0003)$, respectively, in DLD-1 cells $(\mathrm{P}<0.001$; Fig. 3D) compared with the control group. These results indicate that knockdown of mutant p53 expression in CRC cells reduces their viability, and inhibits their ability to migrate and invade.

siRNA silencing of mutant 553 expression inhibits the expression of MMP-9 and promotes the expression of epithelial cell markers in mutant p53-expressing human CRC cell lines. To evaluate the effect of p53 on the E-cadherin, $\beta$-catenin and MMP-9 protein expression, p53-specific (sip53) and negative control (NC) siRNAs were transfected into mutant p53-expressing CRC cell lines (SW480, SW620 and DLD-1). The results demonstrate that p53 protein expression was markedly decreased $48 \mathrm{~h}$ following siRNA transfection in all cell lines compared with the cells transfected with the negative control (Fig. 4). Simultaneously, MMP-9 protein expression was decreased, while E-cadherin and $\beta$-catenin protein expression was increased in SW480 (Fig. 4A), SW620 (Fig. 4B) and DLD-1 (Fig. 4C) cells transfected with siRNA compared with the negative control cells.

\section{Discussion}

Mutation of TP53 is one of the most frequent genetic alterations in all cancer types, including CRC (28). Although mutation of TP53 may lead to loss of wild-type p53 activity, some mutated forms of p53 may result in the gain of oncogenic properties that promote tumor growth and progression (29). The ability of mutant p53 to drive enhanced cell growth, invasion and motility has been confirmed in vitro and in xenograft models (28-32). Previous studies have demonstrated that when endogenous expression of mutant p53 was knocked out, the proliferative capacity and chemoresistance of a number of human cancer cell lines decreased, while in nude mice tumorigenicity was also reduced $(33,34)$. In total, $\sim 50 \%$ of all human cancer is caused by p53 mutations (35).

Previous studies have indicated that miRs have important roles in the pathogenesis of cancer, including the regulation of tumor proliferation, invasion, metastasis and angiogenesis through altering the expression levels of target mRNAs $(24,25)$. It has been reported that $\geq 1,000 \mathrm{miRs}$ are found in the human genome and that the expression $\sim 30 \%$ of the human genome is regulated by miRs (36), highlighting the possibility of the existence of a specific miR that directly regulates $\mathrm{p} 53$ protein 


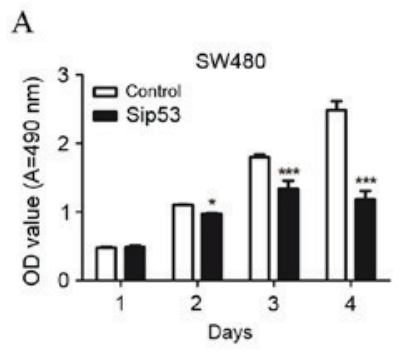

B
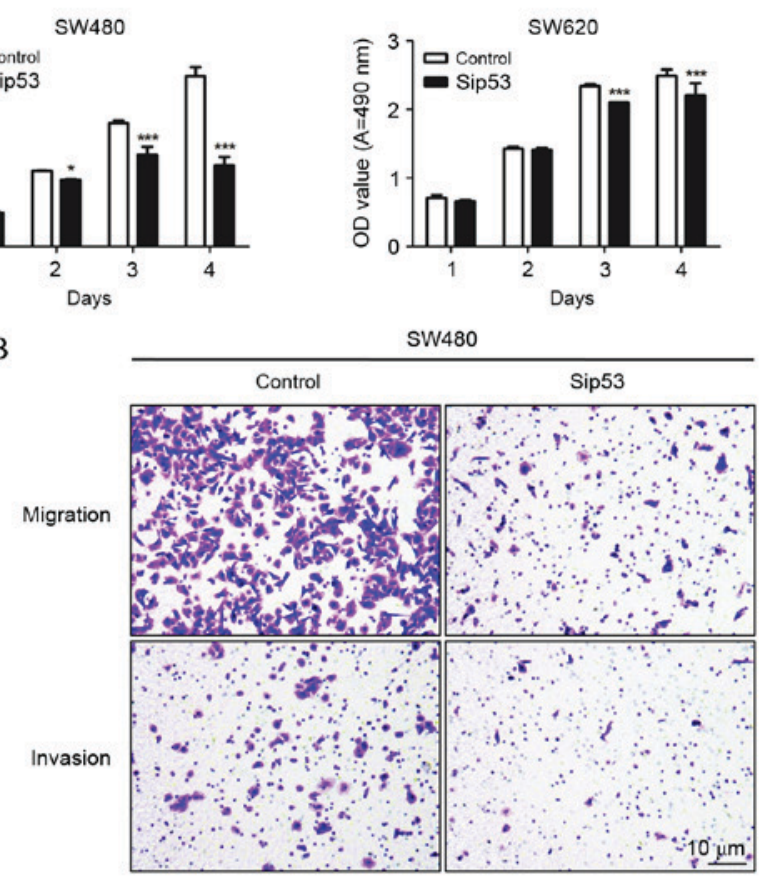

SW480

C
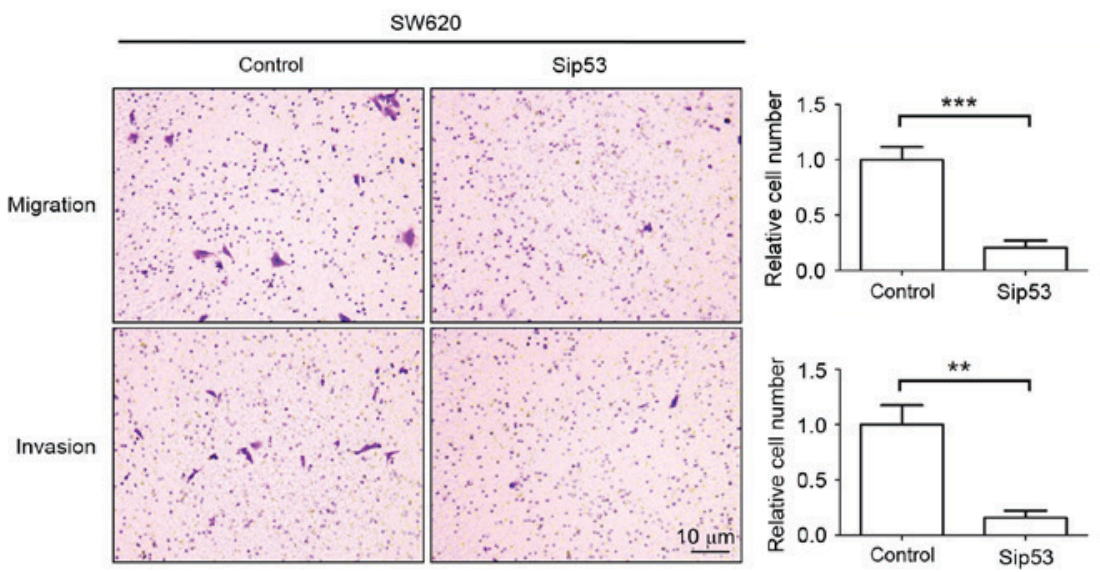

D

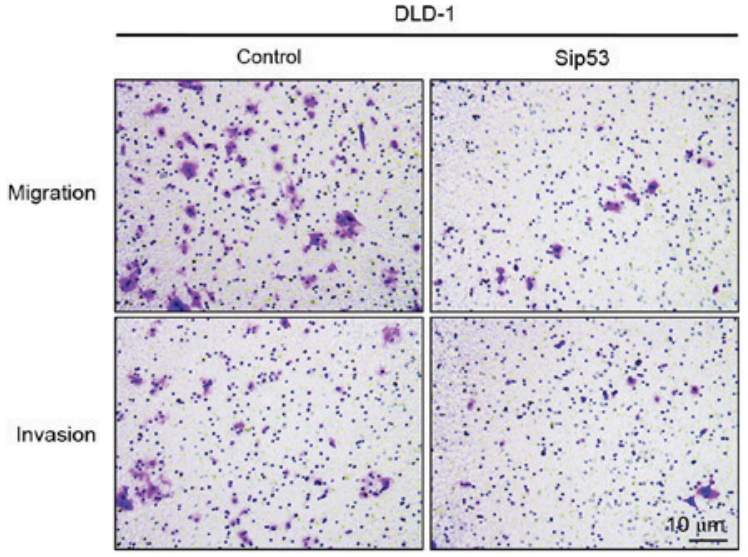

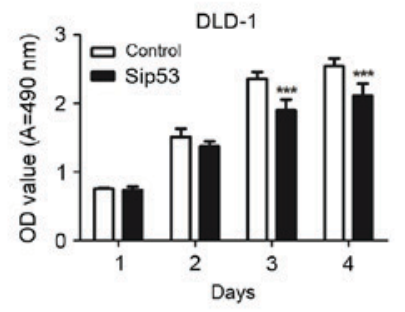
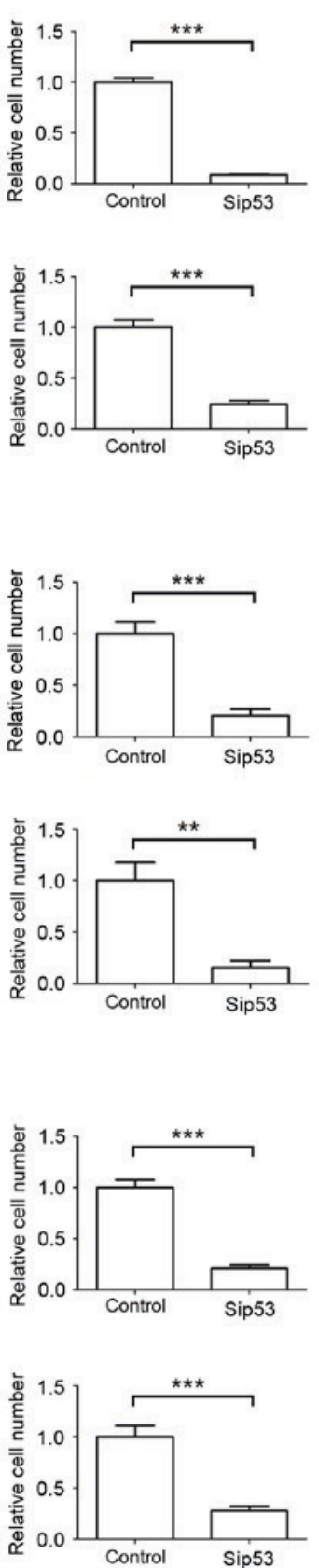

Figure 3. siRNA silencing of p53 expression inhibits colorectal cancer cell proliferation, migration and invasion. (A) The MTT assay was performed to determine the viability of SW480, SW620 and DLD-1 cells transfected with Sip53. A total of $50 \mu \mathrm{M}$ negative control siRNAs or p53 siRNAs were transfected into SW480, SW620 and DLD-1 cells for $48 \mathrm{~h}$. siRNA silencing of p53 expression significantly inhibited (B) SW480, (C) SW620 and (D) DLD-1 cell migration and invasion in a Transwell assay compared to the control group. Magnification, x200; Scale bars, $10 \mu \mathrm{m}$. ${ }^{*} \mathrm{P}<0.05,{ }^{, * *} \mathrm{P}<0.01,{ }^{* * * *} \mathrm{P}<0.001$ vs. the control group. siRNA, small interfering RNA; Sip53, p53-specific siRNA; OD, optical density; A, absorbance.

expression and its subsequent function. In the present study, miR-600 was identified as a direct negative regulator of $\mathrm{p} 53$ through its binding to the 3'UTR of p53 mRNA. In addition, it was demonstrated that overexpression of miR-600 repressed 
A

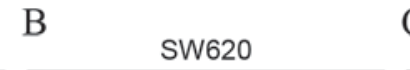

$\mathrm{C}$
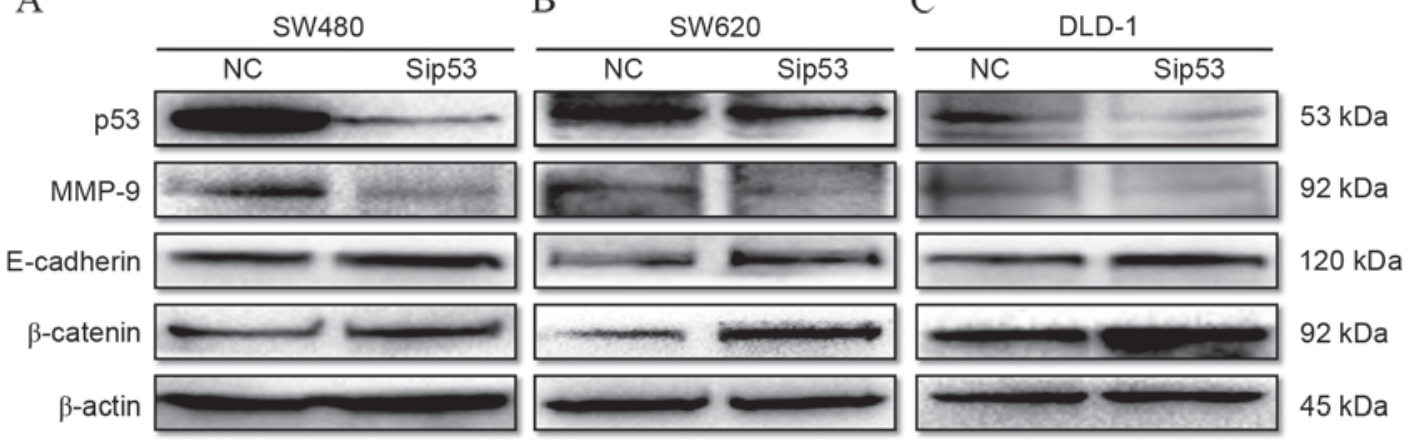

Figure 4. siRNA silencing of p53 expression modulates epithelial-mesenchymal transition-associated protein expression in mutant p53-expressing human colorectal cancer cell lines. Western blot showing the expression of p53, MMP-9, E-cadherin, $\beta$-catenin and $\beta$-actin proteins 48 h following NC or Sip53 siRNA transfection in (A) SW480, (B) SW620 and (C) DLD-1 cells. $\beta$-actin was used as a protein-loading control. siRNA, small interfering RNA; NC, negative control; Sip53, p53-specific siRNA; MMP-9, matrix metalloproteinase 9.

the endogenous level of p53 protein and inhibited cell proliferation, migration and invasion in mutant $\mathrm{p} 53$-expressing human CRC cell lines (SW480, SW620 and DLD-1) in vitro. Knockdown of endogenous mutant p53 by siRNA has been reported to reduce cell growth and chemoresistance in vitro in a number of human cancer cell lines, and inhibit tumor growth in nude mice $(33,34)$. Furthermore, silencing of mutant p53 by siRNA was able to induce cell cycle arrest and apoptosis in human prostate (37) and bladder cancer (38) cells. In the present study, siRNA silencing of p53 produced a similar phenotype to miR-600 overexpression in SW480, SW620 and DLD-1 cells.

MMP family proteins are associated with cardiovascular disease and cancer metastasis, and regulated by p53 (39). It has been reported that wild-type p53 is able to suppress the expression of MMP-9 $(40,41)$. However, a number of mutant p53 proteins do not possess this ability. Prior research has revealed that MMP-9 is able to reduce the expression of E-cadherin (42). In the current study, overexpression of miR-600 and p53 knockdown were observed to suppress MMP-9 expression, and promote the expression of E-cadherin and $\beta$-catenin proteins. E-cadherin and $\beta$-catenin are important for epithelial cell-cell adhesion in the normal epithelium (43). Loss of E-cadherin is an important event in EMT during tumorigenesis (44). A previous study identified that mutant $\mathrm{p} 53$ downregulated E-cadherin expression in the CRC cell line HCT116 (44). Dong et al (45) reported that mutant gain-of-function p53 induces EMT through modulation of the miR-130b-zinc finger E-box binding homeobox 1 axis in endometrial cancer cells. The current study observed that inhibition of mutant p53 expression, through overexpression of miR- 600 or by siRNA silencing of mutant $\mathrm{p} 53$, induced E-cadherin expression in mutant p53-expressing human CRC cell lines.

In conclusion, the present study identified that miR-600 is a direct negative regulator of $\mathrm{p} 53$. Overexpression of miR-600 or siRNA silencing of mutant p53 were observed to inhibit proliferation, migration and invasion, suppress MMP-9 expression, and promote the expression of E-cadherin and $\beta$-catenin in mutant p53-expressing human CRC cell lines. The results of the current study increase the current understanding of the function of miRs in the upstream regulation of p53. In addi- tion, these results indicate that targeting mutant p53 through overexpression of miR-600 is a promising therapeutic strategy for the treatment of CRCs bearing p53 mutations.

\section{Acknowledgments}

The present study was supported by the Zhejiang Province Natural Science Foundation of China (grant nos. LY15H160057 and LY17H160056), the National Natural Science Foundation of China (grant no. 81672385) and Wenzhou Science and Technology Bureau Program (grant no. Y20140667).

\section{References}

1. Haggar FA and Boushey RP: Colorectal cancer epidemiology: Incidence, mortality, survival, and risk factors. Clin Colon Rectal Surg 22: 191-197, 2009.

2. Ferlay J, Shin HR, Bray F, Forman D, Mathers C and Parkin DM: Estimates of worldwide burden of cancer in 2008: GLOBOCAN 2008. Int J Cancer 127: 2893-2917, 2010.

3. Boyle P and Langman J: ABC of colorectal cancer: Epidemiology. BMJ 321: 805-808, 2000.

4. Lech G, Slotwiński R, Słodkowski M and Krasnodębski IW: Colorectal cancer tumour markers and biomarkers: Recent therapeutic advances. World J Gastroenterol 22: 1745-1755, 2016.

5. Kruse JP and Gu W: Modes of p53 regulation. Cell 137: 609-622, 2009.

6. Oren M and Rotter V: Mutant p53 gain-of-function in cancer. Cold Spring Harb Perspect Biol 2: a001107, 2010.

7. Vogelstein B, Lane D and Levine AJ: Surfing the p53 network. Nature 408: 307-310, 2000.

8. Hollstein M, Sidransky D, Vogelstein B and Harris CC: p53 mutations in human cancers. Science 253: 49-53, 1991.

9. Kato S, Han SY, Liu W, Otsuka K, Shibata H, Kanamaru R and Ishioka $\mathrm{C}$ : Understanding the function-structure and function-mutation relationships of p53 tumor suppressor protein by high-resolution missense mutation analysis. Proc Natl Acad Sci USA 100: 8424-8429, 2003.

10. Milner J and Medcalf E: Cotranslation of activated mutant p53 with wild type drives the wild-type p53 protein into the mutant conformation. Cell 65: 765-774, 1991.

11. Milner J, Medcalf EA and Cook AC: Tumor suppressor p53: Analysis of wild-type and mutant p53 complexes. Mol Cell Biol 11: 12-19, 1991.

12. Oren $M$ and Rotter V: Mutant p53 gain-of-function in cancer. Cold Spring Harb Perspect Biol 2: a001107, 2010.

13. Hermeking H: MicroRNAs in the 53 network: Micromanagement of tumour suppression. Nat Rev Cancer 12: 613-626, 2012.

14. Le MT, Teh C, Shyh-Chang N, Xie H, Zhou B, Korzh V, Lodish HF and Lim B: MicroRNA-125b is a novel negative regulator of p53. Genes Dev 23: 862-876, 2009. 
15. Hu W, Chan CS, Wu R, Zhang C, Sun Y, Song JS, Tang LH, Levine AJ and Feng Z: Negative regulation of tumor suppressor p53 by microRNA miR-504. Mol Cell 38: 689-699, 2010.

16. Feng Z, Zhang C, Wu R and $\mathrm{Hu} \mathrm{W}$ : Tumor suppressor p53 meets microRNAs. J Mol Cell Biol 3: 44-50, 2011.

17. Park SY, Lee JH, Ha M, Nam JW and Kim VN: miR-29 miRNAs activate 553 by targeting p85 alpha and CDC42. Nat Struct Mol Biol 16: 23-29, 2009.

18. Yamakuchi M and Lowenstein CJ: MiR-34, SIRT1 and p53: The feedback loop. Cell Cycle 8: 712-715, 2009.

19. Song B, Wang Y, Kudo K, Gavin EJ, Xi Y and Ju J: miR-192 Regulates dihydrofolate reductase and cellular proliferation through the p53-microRNA circuit. Clin Cancer Res 14: 8080-8086, 2008.

20. Pichiorri F, Suh SS, Rocci A, De Luca L, Taccioli C, Santhanam R, Zhou W, Benson DM Jr, Hofmainster C, Alder H, et al: Downregulation of p53-inducible microRNAs 192, 194, and 215 impairs the p53/MDM2 autoregulatory loop in multiple myeloma development. Cancer Cell 18: 367-381, 2010.

21. Manfe V, Biskup E, Rosbjerg A, Kamstrup M, Skov AG, Lerche CM, Lauenborg BT, Odum N and Gniadecki R: miR-122 regulates p53/Akt signalling and the chemotherapy-induced apoptosis in cutaneous T-cell lymphoma. PloS One 7: e29541, 2012.

22. Lee RC, Feinbaum RL and Ambros V: The C. elegans heterochronic gene lin- 4 encodes small RNAs with antisense complementarity to lin-14. Cell 75: 843-854, 1993.

23. Jansson MD and Lund AH: MicroRNA and cancer. Mol Oncol 6: 590-610, 2012.

24. Kasinski AL and Slack FJ: Epigenetics and genetics. MicroRNAs en route to the clinic: Progress in validating and targeting microRNAs for cancer therapy. Nat Rev Cancer 11: 849-864, 2011.

25. Stahlhut $C$ and Slack FJ: MicroRNAs and the cancer phenotype: Profiling, signatures and clinical implications. Genome Med 5: $111,2013$.

26. Jiang L, Lai YK, Zhang J, Wang H, Lin MC, He ML and Kung HF: Targeting S100P inhibits colon cancer growth and metastasis by Lentivirus-mediated RNA interference and proteomic analysis. Mol Med 17: 709-716, 2011.

27. Chen Y, Lin MC, Yao H, Wang H, Zhang AQ, Yu J, Hui CK, Lau GK, He ML, Sung J and Kung HF: Lentivirus-mediated RNA interference targeting enhancer of zeste homolog 2 inhibits hepatocellular carcinoma growth through down-regulation of stathmin. Hepatology 46: 200-208, 2007.

28. Li XL, Zhou J, Chen ZR and Chng WJ: P53 mutations in colorectal cancer-molecular pathogenesis and pharmacological reactivation. World J Gastroenterol 21: 84-93, 2015.

29. Zhou G, Wang J, Zhao M, Xie TX, Tanaka N, Sano D, Patel AA, Ward AM, Sandulache VC, Jasser SA, et al: Gain-of-function mutant p53 promotes cell growth and cancer cell metabolism via inhibition of AMPK activation. Mol Cell 54: 960-974, 2014.

30. Lenfert E, Maenz C, Heinlein C, Jannasch K, Schumacher U, Pantel K, Tolstonog GV, Deppert W and Wegwitz F: Mutant p53 promotes epithelial-mesenchymal plasticity and enhances metastasis in mammary carcinomas of WAP-T mice. Int J Cancer 136: E521-E533, 2015.
31. Ji L, Xu J, Liu J, Amjad A, Zhang K, Liu Q, Zhou L, Xiao J and Li X: Mutant p53 promotes tumor cell malignancy by both positive and negative regulation of the transforming growth factor $\beta$ (TGF- $\beta$ ) pathway. J Biol Chem 290: 11729-11740, 2015.

32. Arjonen A, Kaukonen R, Mattila E, Rouhi P, Högnäs G, Sihto H, Miller BW, Morton JP, Bucher E, Taimen P, et al: Mutant p53-associated myosin-X upregulation promotes breast cancer invasion and metastasis. J Clin Invest 124: 1069-1082, 2014.

33. Bossi G, Marampon F, Maor-Aloni R, Zani B, Rotter V, Oren M, Strano S, Blandino G and Sacchi A: Conditional RNA interference in vivo to study mutant p53 oncogenic gain of function on tumor malignancy. Cell Cycle 7: 1870-1879, 2008.

34. Bossi G, Lapi E, Strano S, Rinaldo C, Blandino G and Sacchi A: Mutant p53 gain of function: Reduction of tumor malignancy of human cancer cell lines through abrogation of mutant p53 expression. Oncogene 25: 304-309, 2006.

35. Khoo KH, Verma CS and Lane DP: Drugging the p53 pathway: Understanding the route to clinical efficacy. Nat Rev Drug Discov 13: 217-236, 2014.

36. He L and Hannon GJ: MicroRNAs: Small RNAs with a big role in gene regulation. Nat Rev Genet 5: 522-531, 2004.

37. Zhu H, Mao Q, Lin Y, Yang K and Xie L: RNA interference targeting mutant p53 inhibits growth and induces apoptosis in DU145 human prostate cancer cells. Med Oncol 28 (Suppl 1): S381-S387, 2011 .

38. Zhu HB, Yang K, Xie YQ, Lin YW, Mao QQ and Xie LP: Silencing of mutant p53 by siRNA induces cell cycle arrest and apoptosis in human bladder cancer cells. World J Surg Oncol 11: 22, 2013.

39. Cohen M, Wuillemin C, Irion O and Bischof P: Regulation of MMP-9 by p53 in first trimester cytotrophoblastic cells. Hum Reprod 23: 2273-2281, 2008.

40. Martelli M, Campana A and Bischof P: Secretion of matrix metalloproteinases by human endometrial cells in vitro. J Reprod Fertil 98: 67-76, 1993.

41. Liu J, Zhan M, Hannay JA, Das P, Bolshakov SV, Kotilingam D, Yu D, Lazar AF, Pollock RE and Lev D: Wild-type p53 inhibits nuclear factor-kappaB-induced matrix metalloproteinase-9 promoter activation: Implications for soft tissue sarcoma growth and metastasis. Mol Cancer Res 4: 803-810, 2006.

42. Nawrocki-Raby B, Gilles C, Polette M, Martinella-Catusse C, Bonnet N, Puchelle E, Foidart JM, Van Roy F and Birembaut P: E-cadherin mediates MMP down-regulation in highly invasive bronchial tumor cells. Am J Pathol 163: 653-661, 2003.

43. Chaw SY, Majeed AA, Dalley AJ, Chan A, Stein S and Farah CS: Epithelial to mesenchymal transition (EMT) biomarkers-E-cadherin, beta-catenin, APC and Vimentin-in oral squamous cell carcinogenesis and transformation. Oral Oncol 48: 997-1006, 2012.

44. Roger L, Jullien L, Gire V and Roux P: Gain of oncogenic function of p53 mutants regulates E-cadherin expression uncoupled from cell invasion in colon cancer cells. J Cell Sci 123: 1295-1305, 2010.

45. Dong P, Karaayvaz M, Jia N, Kaneuchi M, Hamada J, Watari H, Sudo S, Ju J and Sakuragi N: Mutant p53 gain-of-function induces epithelial-mesenchymal transition through modulation of the miR-130b-ZEB1 axis. Oncogene 32: 3286-3295, 2013. 